\title{
Training Needs Assessment for Employability in Pharmaceutical Industries
}

\author{
Athira Balakrishnan, Vijayanarayana Kunhikatta, Sreedharan Nair, Kanav Khera, P. C. Viji, Girish Thunga* \\ Department of Pharmacy Practice, Manipal College of Pharmaceutical Sciences, Manipal Academy of Higher Education, \\ Manipal, India
}

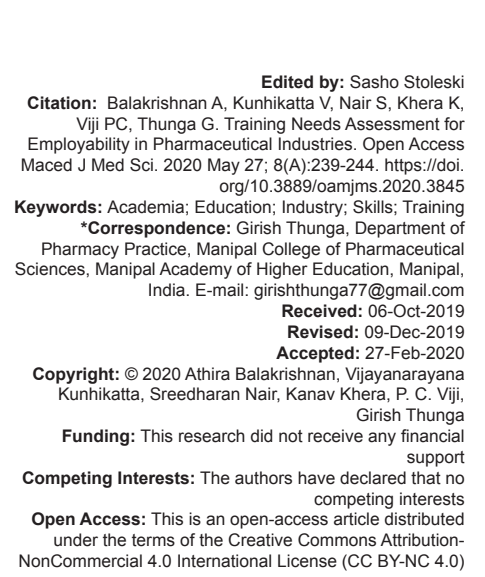

\section{Abstract}

OBJECTIVE: The aim of the study was to assess the perception of final year pharma students, faculties from various Pharmacy Council of India/All India Council for Technical Education approved pharmacy colleges and industria experts toward skill gaps, employability, and job-oriented training programs.

METHODS: Cross-sectional survey conducted using validated piloted questionnaire in both educational and industry sector. Mann-Whitney test was used to analyze difference in opinions of industry professionals and academicians. NVIVO 12(trial version) used to analyze qualitative data from open-ended question.

RESULTS: Both faculty (65\%) and industrial expert (31.5\%) surveyed opined that graduates are lack of skills. It was also observed that basic knowledge and technical skills are the gaps that affect graduates' performance. Most of the students $(94 \%)$, academicians $(92 \%)$, and industry professionals $(93 \%)$ unanimously agreed that there is a strong need of training programs.

CONCLUSION: Revival of pharmacy education incorporating training programs is the need of the hour.

\section{Introduction}

Graduate employability is a global concern with the expansion of higher education and economic downturn [1]. In India, mushroom growth of pharmacy colleges, led to intense competition for job as number of students awarded degree is ascending in each year. Indian pharmaceutical industries, largest provider of generic drugs, are booming and expected to become US $\$ 55$ billion market by 2020 [2]. Question arises here is, do pharma students possess adequate skills and attributes to meet industrial requirements. A famous quote by Manfred Eigen, Nobel laureate, "In theory, there is no difference between theory and practice but in practice there is, enlighten us to sense the present scenario in pharmaceutical education." Stark reality Indian pharma encounters now is, pharma graduates are not being skilled enough to hire. Even if they hire, entry level employees need extensive training before they start [3]. Various studies have been done to identify the skills for the development of pharmacist and considerable agreement has been found among different pharma professionals on the skills valued most [4], [5]. However, it is important to ascertain the perception of various pharma professionals including students about the skills required for employment in industry and noteworthy point is, there are limited numbers of pedagogical studies to evaluate the students' perception [6]. A study by Scott et al. [7] to improve students' employability skills revealed there is a sense of urgency to recognize students' exposure to employment skills to assure that what is being delivered is relevant. Accordingly this study is aimed to evaluate the perception of various pharma professionals toward skill gap that exists between industry and academia.

\section{Materials and Methods}

\section{Study design}

A cross-sectional survey was conducted using self-administered questionnaires and Google forms.

\section{Ethical consideration}

Study has registered institutional ethics committee in Kasturba Hospital, Manipal, India, and clinical trial registry of India (CTRI/2018/03/012335). 
Consent from head of the institution from every participating college has taken which states their willingness to participate in this study. Participant information sheet (PIS) was provided to all participants. Principal investigator explained in detail about the survey and has taken informed consent form from each and every participant. For online survey, participants were able to assess the form only after giving their consent.

\section{Data collection tool}

There were two questionnaires, first questionnaire was focused on final year pharma graduates and postgraduates, and second questionnaire focused on faculties from All India Council for Technical Education/Pharmacy Council of India approved pharmacy colleges and industrial experts having minimum of 3 year experience. The first questionnaire composed of 13 multiple choice question and one open-ended question. Multiple choice questions were based on opportunities in pharma industry, perception about graduates' professional skills, and perception about training. Second questionnaire was composed of nine questions related to perception about graduates' professional skill, perception about curriculum, and perception about training.

\section{Questionnaire development and validation}

Initial draft content of the questionnaires was developed on the basis of the literature review and informal discussion with experts. The questionnaire was validated by five experts for its content validity. Questions having item content validity index $<0.78$ removed from the questionnaire. Scale content validity index was 0.92 [8], [9].

\section{Sample size calculation} formula.

Sample size was calculated using following

$N=Z \alpha 2 \times p(1-p) / d 2$. Calculated sample size was 323 for students, 100 for academicians and 73 for industry professionals.

Where $Z=$ standard normal variate $(Z=1.96$ when confidence interval is $95 \%), P=$ proportion of outcome in the population (based on pilot study), and $d$ is the precision (0.05) [10].

\section{Data collection methods}

A survey was conducted in two deemed universities in South India, and colleges affiliated to Kerala university of health sciences (A total of nine colleges participated) in 2018. Sampling method was non-probability convenient sampling method. (Colleges names cannot be disclosed due to ethical considerations and were taken ethics committee approval from Kasturba Hospital, Manipal, India). The survey was conducted using validated questionnaires for a period of 7 months. Permission letter from each colleges showing their willingness to participate in this study was taken and it was informed that colleges' or participants' names will not be disclosed anywhere.

Principal investigator personally visited pharmacy colleges and conducted survey for student population. The questionnaires were distributed to students who are interested to participate in the study. PISs were given to participants and collected signed informed consent form.

For academicians, data collected using both direct survey and Google forms. The questionnaire was distributed to those whomever were free and showed interest at the time of Principal Investigator's visit. Academicians whoever were busy at that time, or who could not submit the questionnaire, principal investigator sent an email with description of the study and Google form link. For this, Email ids of academicians were collected from respective colleges. Participants can access Google forms only after giving their consent.

For industrial expert, data collection method was purely using online Google forms and most of the industrial experts were our college alumni who are working in various pharmaceutical industry. Email ids of alumni were collected from LinkedIn/Facebook and college office. Furthermore, email sent with Google form link to one life science company in South India dealing with Clinical Development, Regulatory Affairs and Pharmacovigilance. It was informed to them company name or participants name will not be disclosed anywhere. Participants can access online questionnaire only after giving informed consent form.

\section{Data analysis}

The data tabulated from questionnaire survey sheet were transformed from alphabet coding to numerical coding. Quantitative variable was analyzed by descriptive statistics using SPPS 20. Chi-square test has been done for finding association between categorical variables. Mann-Whitney U-test has been done to find out the difference in the opinions of faculties and industrial experts as most of the responses were in Likert scale. Statistical significance was defined as $\alpha<0.05$. Thematic analysis using NVIVO software version 12 (Trial version) was used to analyze response from open-ended question.

\section{Results}

To reach the recommended minimum sample size for academicians ( $n=100), 246$ surveys were 
distributed, which gives a response rate of $40.655 \%$. For industrial experts, 205 survey questionnaires mailed. Of these, a total of 73 were completed, giving a response rate of $35.6 \%$. Table 1 summarizes the perception of industry professionals and academicians.

More than three quarters of faculties and industry professionals ( $88 \%$ and $89 \%$ ) surveyed viewed that there exist a gap. Mann-Whitney test was applied to find whether there is a difference in the opinion among the respective groups. $p=0.765$ was found which indicates that the opinion of both the groups is similar and they are of the view that there exists a gap in the curriculum being taught and the requirements of the industry.

Further, it was required to find whether additional training program is needed for pharma students to achieve their goals or professional competency. Most of the pharma professional were positive about this (85\% and $82.1 \%$ ). Overall, percentage of respondents indicating the need of additional training programs is tabulated in Table 1 and $p=0.547$ was found. $p$ value shows there is no significant variation observed in the opinions of faculties and industry professionals.

Asked if training will boost graduates' confidence level, over three-quarters $(92 \%$ and $93.2 \%$ ) stated that it would. $p=0.693$ was found and it indicated both professionals agreed additional training program will increase graduates' confidence level and professional standards.

The percentage responses of faculty and industrial expert with respect to the pharma syllabus (both graduation and postgraduation level) meets all industrial needs were $12 \%$ and $23.3 \%$. Curriculum needs to be revised as evidenced from maximum preferences of $53.5 \%$ (industrial experts and $78 \%$ (faculty). However, there was significant difference in opinions of both professionals $(p=0.01)$. It could be due to many industry professionals opted neutral (23\%) as their response to this question.

Most of the academicians (65\%) surveyed viewed pharma graduates' are lack of skills. Surprisingly,
$31.5 \%$ industry professionals agreed or strongly agreed to this point. About $20.5 \%$ of industry professionals were unsure about their answerers.

When describing about gaps that directly affect students' performance, 64\% academicians' opted lack of basic knowledge and technical skills (ability to execute) are affecting students' performance. A total of $49.3 \%$ of industrial expert agreed to this point, but $38.4 \%$ indicate that technical skills are the gap that affects students' performance. There is no significant difference of opinions of pharma professionals as indicated by $p=0.186$ (Table 2).

Pharma professionals identified a number of barriers that they felt would prevent students' from attending training program. The main obstacles were lack of time, lack of resource, and lack of money (Table 3).

Most of the academicians (79\%) indicated they expect both basic knowledge and technical skill from training but most of the industry professionals (72.6\%) opted for technical skills (Table 4). There were no disagreements between respondents as indicated by $p=0.052$ ).

There is not much significant difference of opinions of pharma professionals in their answers except a few. That could be due to either they are unsure about their answers or mind set of academia and industry is different.

\section{Results from Pharma Students}

A total of 323 completed questionnaires were received back from participants. Questionnaire distributed to only those who are interested to participate in this study. Most of the students (67.5\%) are aware about the opportunities in pharmaceutical fields such as clinical research, medical writing, pharmacovigilance, and clinical data management.

Table 1: Perception of industry professionals and academicians toward skill gap and training programs

\begin{tabular}{|c|c|c|c|c|c|c|c|c|}
\hline $\begin{array}{l}\text { S. } \\
\text { No }\end{array}$ & Questions & Pharma professionals & Strongly agree (\%) & Agree (\%) & Neutral (\%) & Disagree $(\%)$ & Strongly disagree (\%) & $\mathrm{p}$-value \\
\hline 1 & $\begin{array}{l}\text { Graduates possess adequate professional } \\
\text { skills }\end{array}$ & $\begin{array}{l}\text { Academicians } \\
\text { Industry professionals }\end{array}$ & $\begin{array}{l}5(5) \\
8(11)\end{array}$ & $\begin{array}{l}18(18) \\
27(37)\end{array}$ & $\begin{array}{l}12(12) \\
15(20.5)\end{array}$ & $\begin{array}{l}57(57) \\
14(19.2)\end{array}$ & $\begin{array}{l}8(8) \\
9(12.3)\end{array}$ & 0.00 \\
\hline 2 & $\begin{array}{l}\text { Pharma Graduates can meet professional } \\
\text { competency without a proper training }\end{array}$ & $\begin{array}{l}\text { Academicians } \\
\text { Industry professionals }\end{array}$ & $\begin{array}{l}2(2) \\
4(5.5)\end{array}$ & $\begin{array}{l}10(10) \\
15(20.5)\end{array}$ & $\begin{array}{l}3(3) \\
6(8.2)\end{array}$ & $\begin{array}{l}59(59) \\
34(46.6)\end{array}$ & $\begin{array}{l}26(26) \\
14(19.2)\end{array}$ & 0.004 \\
\hline 3 & $\begin{array}{l}\text { Pharma graduates current syllabus meet all } \\
\text { industrial needs }\end{array}$ & $\begin{array}{l}\text { Academicians } \\
\text { Industry professionals }\end{array}$ & $\begin{array}{l}2(2) \\
3(4.1)\end{array}$ & $\begin{array}{l}10(10) \\
14(19.2)\end{array}$ & $\begin{array}{l}10(10) \\
17(23.3)\end{array}$ & $\begin{array}{l}59(59) \\
31(42.5)\end{array}$ & $\begin{array}{l}19(19) \\
8(11)\end{array}$ & 0.01 \\
\hline 4 & $\begin{array}{l}\text { There is a gap between industry and } \\
\text { academia }\end{array}$ & $\begin{array}{l}\text { Academicians } \\
\text { Industry professionals }\end{array}$ & $\begin{array}{l}54(54) \\
22(30.1)\end{array}$ & $\begin{array}{l}34(34) \\
43(58.9)\end{array}$ & $\begin{array}{l}2(2) \\
4(5.5)\end{array}$ & $\begin{array}{l}5(5) \\
3(4.1)\end{array}$ & $\begin{array}{l}5(5) \\
1(1.4)\end{array}$ & 0.765 \\
\hline 5 & $\begin{array}{l}\text { Pharma graduates need additional training to } \\
\text { achieve goals }\end{array}$ & $\begin{array}{l}\text { Academicians } \\
\text { Industry professionals }\end{array}$ & $\begin{array}{l}49(49) \\
25(34.2)\end{array}$ & $\begin{array}{l}36(36) \\
35(47.9)\end{array}$ & $\begin{array}{l}7(7) \\
3(4.1)\end{array}$ & $\begin{array}{l}1(1) \\
7(9.6)\end{array}$ & $\begin{array}{l}7(7) \\
3(4.1)\end{array}$ & 0.547 \\
\hline 6 & $\begin{array}{l}\text { Training will enhance graduates confidence } \\
\text { level }\end{array}$ & $\begin{array}{l}\text { Academicians } \\
\text { Industry professionals }\end{array}$ & $\begin{array}{l}62(62) \\
38(52.1)\end{array}$ & $\begin{array}{l}30(30) \\
30(41.1)\end{array}$ & $\begin{array}{l}0 \\
4(5.5)\end{array}$ & $\begin{array}{l}2(2) \\
1(1.4) \\
\end{array}$ & $\begin{array}{l}6(6) \\
0\end{array}$ & 0.693 \\
\hline
\end{tabular}

p-value has been calculated using Mann-Whitney test. $p<0.05$ considers statistically significant.

Table 2: Perception of academicians and industry professionals toward gaps affecting graduates' performance

\begin{tabular}{lllll}
\hline Question & Pharma professionals & Basic knowledge $(\%)$ & Technical skill (\%) & Both basic knowledge and technical skill (\%) \\
\hline Gaps that directly affect fresh & Academicians & $3(3)$ & $30(30)$ & $64(64)$ \\
graduates performance & Industry professionals & $3(4.1)$ & $28(38.4)$ & $36(49.3)$ \\
\hline p value has been calculated using Chi-square test. $p<0.05$ considers statistically significant. & & \\
\hline
\end{tabular}


Table 3: Perception of academicians and industry professionals toward obstacles for attending training program

\begin{tabular}{|c|c|c|c|c|c|c|c|}
\hline Question & Pharma professionals & Lack of time $(\%)$ & Lack of resource (\%) & Lack of money (\%) & All of the above (\%) & Others (\%) & $\mathrm{p}$-value \\
\hline Major obstacles for & Academicians & $3(3)$ & $21(21)$ & $3(3)$ & $69(69)$ & $4(4)$ & 0.391 \\
\hline attending training program & Industry professionals & $6(8.2)$ & $11(15.1)$ & $2(2.7)$ & $53(72.6)$ & $1(1.4)$ & \\
\hline
\end{tabular}

$p$ value has been calculated using Chi-square test. $p<0.05$ considers statistically significant

Table 4: Perception of academicians and industry professionals toward skills they expect from training

\begin{tabular}{lllll}
\hline Question & Pharma professionals & Basic knowledge $(\%)$ & Technical skill $(\%)$ & Both basic knowledge and Technical skill (\%) \\
\hline Skills expect from a & Academicians & $1(1)$ & $20(20)$ & $79(79)$ \\
training & Industry professionals & $14(19.2)$ & $53(72.6)$ & $6(8.2)$ \\
\hline p value has been calculated using Chi-square test. p $<0.05$ considers statistically significant. & & 0.052 \\
\hline
\end{tabular}

$p$ value has been calculated using Chi-square test. $p<0.05$ considers statistically significant.

\section{Perception about professional skills}

According to graduates (47.7\%), they do not possess adequate skills and attributes to meet the professional competency. Maximum percentage of students $(53.3 \%)$ responded that they are lack of both basic knowledge and technical skills (ability to execute) and some of the students $(35.6 \%)$ surveyed opined that practical skills are the gap that affect their performance.

\section{Perception about training}

A total of $41.8 \%$ students shared that they are not at all aware about the online training programs. Some of the students (35.6\%) are not attending any training program align to their career interest during their graduation span. Among them, 21.4\% responded that time is the major obstacle for attending training program. Most of the students (94.4\%) supported that there is a strong need of training. However, only $35.9 \%$ prefer online training program than offline. This might be because few of them are aware of online training courses. Other findings are summarized in Table 5.

One question was open-ended and students were invited to comment on what expectation do they have from a professional training. Data analyzed thematically using NVIVO (trial version) software. Initial analysis identified 16 themes related to new pedagogies, skills they expect from training, online courses, and inclusion

Table 5: Students' perception

\begin{tabular}{ll}
\hline Question & $\begin{array}{l}\text { Response of students } \\
(\%) \mathbf{n = 3 2 3}\end{array}$ \\
\hline $\begin{array}{l}\text { Awareness about online training program } \\
\text { Students who are not attending any training program, }\end{array}$ & 45.8 \\
workshops, or seminars & 29.7 \\
$\begin{array}{l}\text { Lack of time, lack of money, and lack of resources are the major } \\
\text { obstacle for attending training program }\end{array}$ & 47.7 \\
Skills expect from training & Basic knowledge + \\
& Technical skill - $73.4 \%$ \\
\hline
\end{tabular}

of case studies and simulation. These 16 themes were further grouped into four overarching themes as follows.

- $\quad$ Conduct a training program which is more industry relevant, practical oriented, and scope based. It should enhance students' confidence level and opportunity to get recruitment

- $\quad$ Orientate training program to improve students understanding of the subject and how to apply these concepts when it comes in practical scenario
- As time is major constraint, self-directive, online training programs enriched with case studies and simulation can conduct as per students' needs or interest

- $\quad$ Pre- and post-test can be taken to evaluate the effectiveness of training program.

\section{Discussion}

Overall, this study has identified many interesting findings of the perception of pharma students, academicians, and industry professionals about graduates professional skills, whether additional training is needed or curriculum needs to be updated with industrial requirements, and what skills they expect from a training .Most of the pharma professionals had a positive perception of the gap that exists between industry and academia. This study finding is in accordance with prior research by Gawade and Sonaje [11] in which most of the pharma professionals felt that there exists a gap between industry and academia in pharmaceutical education. However, on the other hand, when they were asked whether the curriculum meets all industrial requirement there is a significant difference in the opinions of academicians and industry professionals. This might be because respondents were not sure about what extent curriculum can modify as it is a heterogeneous blend of industrial and clinical subjects. This is because they suggested additional training aligned to students' career interest is needed to achieve their goals. A recent report by American Association of College of Pharmacy described, Pharmaceutical Science graduate programs are designed to conduct academic research and traditional educational approach fails to prepare students who embark into non-academic career. Report recommended creating a task force to determine the need of specific core and specialty curriculum and industry must work more closely with regulators [12].

Another key finding of this study was students do not prefer online training programs. This could be because only few are aware of online training programs. It is also reported that $24.8 \%$ students never attended any workshops, training programs, seminars, and conferences. Students felt major obstacles for attending 
training programs are lack of time, lack of resource, and lack of money. Industrial professional and faculties also agreed to this point and they added students had a perception that conferences/seminars are conducted as mere formality and there is no usefulness to attend. Hence, they recommend students need to attend training programs based on their area of interest or choice and conference has to be conducted as per students' needs.

Interestingly, industry professional surveyed had a positive perception of students' professional skills. However, academicians significantly differed from industry professionals on this view point. Same question was asked to student population to understand their perception about skills they possess. A concerning finding of this study, however, is that students revealed they are lack of skills to meet professional competency. Most of them opined they are adept at basic knowledge or theoretical knowledge but not sure about how to deal when it comes to practical scenario. Despite basic knowledge and technical skills, industry professionals enumerated soft skills are either deficient or absent in graduates. A study by Garces and Black [13] on soft skills concluded that graduate programs should make students to possess both technical skills and soft skills to nimble them diverse employment needs. Our study result reflected same. Academicians pointed out that what is learned from theory class is different when it comes into practice. No one knows how much theory learned from class is connected to practice. They indicated students need training in the actual setting at least 6 months-1 year before their graduation. It was gratifying to find that there was strong convergence of student/graduate, academicians, and employer perceptions of the gaps that affect graduates' performance and skills they expect from training.

Almost all participants (students, academicians, and industry professionals) unanimously agreed inclusion of training programs in curriculum which is aligned to students' career interest is cardinal to make them more competent and confident. This study result mirrored the study findings of Palsokar and Tajne [14] who conducted a study about perceived gap between industry and academia. As there are few empirical studies in the area of pharmaceutical education in lowand middle-income countries [15], there is a strong need for more robust studies to address the gap between industry and academia.

\section{Strength and limitation of the study}

The questionnaires were simple, objective specific and there was no usage of confused terminology/ jargon and there was enough sample size for student population which increases the generalizability of the findings. Before start of data collection, we provide them clear introduction about the purpose of study, thus we believe this has not influenced the quality of the collected data.
The major limitation in this study is the low survey response rate from academicians and industrial experts, which could contribute to nonresponse bias. It is not uncommon to see the low response rate with web-based survey than direct survey (paper-based survey) [16]. In addition, due to the low response rate and anonymous nature of the survey, there is no way to tell whether the surveyed population is representative of all regions. Finally, demographic section of survey instrument did not ask about participants' (industry professional and academicians) experience in years though all possess more than 2 years.

\section{Conclusion}

This study concluded that students need training programs which emphasizes practical aspects to achieve their goals as they are ambiguous to apply theoretical concepts to practical scenario. Training program should be conducted as per students' career interest or choices. Inclusion of case studies and simulation lab in curriculum will help to provide realistic experience and promote specialized and focused way of learning.

\section{References}

1. Tomlinson M. Graduate employability: A review of conceptual and empirical themes. Higher Educ Policy. 2012;25(4):407-31. https://doi.org/10.1057/hep.2011.26

2. IBEF. Industry Pharma Industry in India: Pharma Sector Overview, Market Size, Analysis. New Delhi: IBEF; 2019. Available from: https://www.ibef.org/industry/pharmaceuticalindia.aspx. [Last accessed on 2019 Mar 08].

3. India to Face Acute Dearth of Productive and Employable Pharmacy Graduates: Uma Nandan Misra; 2019. Available from: http://www.pharmabiz.com/newsdetails. aspx?aid=110544\&sid=1. [Last accessed on 2019 Feb 08].

4. Wilbur K, El-Awaisi A, Paravattil B, Zolezzi M, Pawluk S. Contemporary professional skills development for pharmacists in the Middle East. Am J Pharm Educ. 2017;81(10):6042. https:// doi.org/10.5688/ajpe6042 PMid:29367770

5. Jishnu V, Gilhotra R, Mishra D. Pharmacy education in India: Strategies for a better future. J Young Pharm. 2011;3(4):334-42. https://doi.org/10.4103/0975-1483.90248 PMid:22224042

6. Jacob B, Peasah S. Evaluation of first year student pharmacists perceptions of the pharmaceutical industry. Curr Pharm Teach Learn. 2018;10(5):637-42. https://doi.org/10.1016/j. cptl.2018.01.005

PMid:29986824

7. Scott FJ, Connell P, Thomson LA, Willison D. Empowering students by enhancing their employability skills. J Furth High Educ. 2017;16:1-6

8. Almanasreh E, Moles R, Chen TF. Evaluation of methods 
used for estimating content validity. Res Social Adm Pharm. 2019;15(2):214-21. https://doi.org/10.1016/j. sapharm.2018.03.066

PMid:29606610

9. Rodrigues I, Adachi J, Beattie K, MacDermid J. Development and validation of a new tool to measure the facilitators, barriers and preferences to exercise in people with osteoporosis. BMC Musculoskelet Disord. 2017;18(1):540. https://doi.org/10.1186/ s12891-017-1914-5

PMid:29258503

10. Charan J, Biswas T. How to calculate sample size for different study designs in medical research? Indian J Psychol Med. 2013;35(2):121-6. https://doi.org/10.4103/0253-7176.116232 PMid:24049221

11. Gawade S, Sonaje N. Designing of curriculum aspects of pharmacy undergraduate course in respect of graduate employability. Indian J Pharm Educ Res 2017;51:502-9. https:// doi.org/10.5530/ijper.51.4.78

12. Wu-Pong S, Gobburu J, O'Barr S, Shah K, Huber J, Weiner D. The future of the pharmaceutical sciences and graduate education:
Recommendations from the AACP graduate education special interest group. Am J Pharm Educ. 2013;77(4):S2. https://doi. org/10.5688/ajpe774s2

PMid:23716757

13. Garces H, Black E. Corporate communication strategies are applicable for teaching non-science communication skills to pharmaceutical sciences PhD. Curr Pharm Teach Learn 2015;7(2):265-72. https://doi.org/10.1016/j.cptl.2014.11.003

14. Palsokar G, Tajne M. A study on the perceived gap in between industry and academia with reference to the curriculum of postgraduate courses in pharmaceutical sciences in India. Indian J Pharm Educ Res 2018;52:10-20. https://doi.org/10.5530/ ijper.52.1.2

15. Babar Z, Scahill S, Akhlaq M, Garg S. A bibliometric review of pharmacy education literature in the context of low-to middleincome countries. Curr Pharm Teach Learn. 2013;5(3):218-32. https://doi.org/10.1016/j.cptl.2013.01.001

16. Kaplowitz MD, Hadlock TD, Levine R. A comparison of web and mail survey response rates. Public Opin Q. 2004;68:94-101. https://doi.org/10.1093/poq/nfh006 